\title{
Sobre cómo la cámara puede mostrar la crianza vulnerable desde una mirada inclusiva
}

On how the camera can show vulnerable childrearing from an inclusive gaze/point of view

\author{
Nicolás Lorite García \\ Profesor Titular, Departamento de Publicidad, Relaciones Públicas y Comunicación Audiovisual, Universidad Autónoma de \\ Barcelona (España). \\ nicolas.lorite@uab.cat
}

\section{CRIANZA EN CONTEXTOS DE VULNERABILIDAD SOCIOCULTURAL MONOGRÁFICO COORDINADO POR JORGE GRAU REBOLLO}

\begin{abstract}
RESUMEN
Este artículo va destinado a reflexionar sobre cómo la cámara puede incorporar de manera inclusiva la crianza vulnerable. Para ello se recogen ciertas pistas teóricas y metodológicas desde los procesos edu-investigadores que vinculan la docencia con la investigación y ambas con la dinamización sociocultural, desde los modelos de investigación audiovisual aplicada e investigaciónacción. El origen de la propuesta viene de un proyecto competitivo interdisciplinar que analiza el abordaje de este tipo de vulnerabilidad por parte de la publicidad y se preocupa por proponer una campaña inclusiva alternativa desde la multimodalidad metodológica. Un colectivo que experimenta estas diferentes miradas es el de los futuros/as publicitarios/as (alumnado de la asignatura de Realización Audiovisual Publicitaria del Grado de Publicidad y Relaciones Públicas de la Universitat Autònoma de Barcelona del curso 2020/21). Se abordan sus propuestas de buenas prácticas, teniendo en cuenta que forman su conocimiento audiovisual y su conciencia ética, desde modelos de pedagogía activa y constructivista que contemplan este tipo de sinergias.
\end{abstract}

\begin{abstract}
This article intends to reflect on how the camera can inclusively incorporate vulnerable parenting. For this purpose, theoretical and methodological clues are collected within the classroom, particularly from the educational-research processes that occur when linking teaching with research and both with sociocultural dynamization, from the models of applied audiovisual research and action research. The proposal comes from a competitive interdisciplinary project that prioritises how advertising addresses this vulnerability and proposes an inclusive alternative campaign. The camera's gaze at campaigning is addressed from a methodological multimodality by collecting multiple viewpoints from the production, issuance, reception and dynamization of the message. A collective that -experiences these different looks is that of future advertisers (students of the subject of Advertising Audiovisual Production of the Degree in Advertising and Public Relations of the Autonomous University of Barcelona in the 2020/21 academic year). Their best practices proposals are considered here within models of active and constructivist pedagogy as such proposals shape their audiovisual knowledge as well as their ethical awareness.
\end{abstract}

PALABRAS CLAVE

cámara | crianza vulnerable | edu-investigación | audiovisual | publicidad

KEYWORDS

camera | vulnerable childrearing | edu-research | audiovisual | advertising

\section{1. ¿Qué se estudia y por qué?}

El objetivo principal de este texto es mostrar como la cámara puede representar de manera inclusiva la crianza vulnerable y hacerlo usando un alfabeto audiovisual propio (Fernández Diez 1999, García y Menéndez 2007, Ferrés 2005 y Millerson 2001). Se acude a un sistema de signos audiovisuales que es posible delimitar a partir del contraste de puntos de vista que posibilita la metodología multimodal y su vinculación con la investigación audiovisual aplicada y la investigación-acción desde el aula (Ferrés 1994).

Una de las líneas de investigación que se tienen en cuenta para estudiar la crianza vulnerable, desde la perspectiva transversal e interdisciplinar con que se debe investigar (1), es la de la comunicación audiovisual $\mathrm{y}$, en concreto, la de la función dinamizadora sociocultural inclusiva de lenguajes tan sumamente impactantes en el imaginario colectivo como son los publicitarios (Ricarte 1998). Es una perspectiva investigadora que va destinada a comprender qué elementos de la gramática audiovisual intervienen y qué discursos o productos se estructuran y editan, tomando como referencia la teoría del montaje (Eisenstein 2001 y Morales 2017), para difundir los modelos de representación audiovisual más 
adecuados de este tipo de vulnerabilidad y suscitar respuestas dinamizadoras socioculturales inclusivas.

A continuación, se sintetiza el proceso edu-investigador realizado con el alumnado de la asignatura de Realización Audiovisual Publicitaria del Grado de Publicidad y Relaciones Públicas. En concreto, se muestra cómo se aborda en el aula el tema de la crianza vulnerable desde la mirada inclusiva de la cámara. La propuesta parte de un proyecto de investigación y su abordaje en las clases permite aprender a diferenciar cuales son los elementos audiovisuales fundamentales (ideas e imágenes con sus respectivos eslóganes, estilos narrativos y propuestas conceptuales) para la producción de la buena práctica. Participan en este proceso un profesorado que colabora con el proyecto de investigación y aplica modelos de pedagogía activa y constructivista (Coll y otros 1999). Son procesos que se vinculan además con la producción publicitaria audiovisual, y con los organismos encargados de regular y cuidar la aplicación de buenas prácticas como el Consell de l'Audiovisual de Catalunya (Consejo Audiovisual de Cataluña) y el Col-legi de Publicitaris i Relacions Publiques de Catalunya (Colegio de Publicitarios y Relaciones Públicas de Cataluña).

\section{Sobre la investigación audiovisual aplicada desde el aula}

Uno de los ámbitos de recogida de ideas para la campaña publicitaria audiovisual inclusiva sobre la crianza vulnerable es el aula y en concreto el alumnado de la asignatura Realización Audiovisual Publicitaria, de $3^{\text {er }}$ curso del Grado de Publicidad y Relaciones Públicas. A continuación, se sintetiza en qué consiste esta perspectiva edu-investigadora, cómo se combina con la investigación audiovisual aplicada y la investigación-acción, y cómo ambas se plasman a partir de modelos de pedagogía activa y constructivista (Lorite 2001) destinados a educar, concienciar y fomentar en el alumnado la producción de propuestas audiovisuales publicitarias dinamizadoras de las relaciones socioculturales inclusivas.

Esta propuesta pedagógico-investigadora viene implementándose desde diferentes experiencias educomunicativas recogidas por Ferrés (1994 y 2005), Pérez Tornero (2000), Aparici (2010), Aguaded (2012), Ferrés y Piscitelli (2012), Maldonado (2013 y 2018). Es preferible aplicar el calificativo de eduinvestigadora porque:

a) Forma al alumnado de manera transversal e interactiva en la epistemología, teoría, metodología y práctica de la investigación audiovisual aplicada.

b) Lo habitúa a incorporar los valores sociales inclusivos a los productos audiovisuales realizados.

c) Lo socializa, partiendo del concepto de socialización secundaria de Berger y Luckman (2008), con las prácticas inclusivas para que puedan ejercerlas desde cualquiera de sus futuras responsabilidades ciudadanas y/o profesionales.

d) Le enseña a fomentar su conocimiento reglado y científico desde un pensamiento exclusivamente audiovisual que le permita instruirse no solo para realizar un análisis crítico-constructivo de los mensajes audiovisuales, sino para su capacitación en todo lo referente a la producción, realización y representación inclusiva de la sociedad desde los usos cotidianos de las normalizadas pantallas interactivas en red, fruto de la expansión de la convergencia mediática y que cada vez ocupan un lugar más destacado en la comunicación interpersonal e intergrupal global, preconizada por Negroponte (1995) y Echevarría (1995).

Una función principal de la investigación audiovisual aplicada es la de enseñar al alumnado a discurrir del análisis de la producción audiovisual a la realización audiovisual alternativa y sin que sienta que, al realizar ese ejercicio cognitivo y teórico-práctico audiovisual, descuida su formación académica reglada tradicional (Lorite 2001 y 2015). Se trata de posicionar el proceso edu-investigador en el ámbito científico que les corresponde a las ciencias de la comunicación audiovisual y que nada tiene que ver con la estereotipación del audiovisual como producto meramente ocioso, lúdico y hasta según cómo banal o transmisor de comportamientos culturales alienantes, como muy bien se han encargado de señalar ciertas escuelas de pensamiento crítico con la función manipuladora de los discursos de los medios de comunicación e información (Van Dijk 1991).

Sobre esta manera de hacer didáctica y científica del audiovisual se viene teorizando desde las primeras producciones cinematográficas y fotográfica, desde la misma conexión con la antropología (Achutti 1997, 
Buxó 1998) y con las ciencias de la educación, en particular desde que se implanta la comunicación electrónica y plantea actualizar los modelos de innovación educativa, la lingüística o las artes visuales.

Calificamos a la investigación audiovisual como aplicada porque los procesos edu-investigadores experimentados en el aula van orientados a producir mensajes audiovisuales alternativos destinados a dinamizar las relaciones sociales y socioculturales y propiciar cambios inclusivos. Para ello, se actúa en dos ámbitos distintos, aunque complementarios, como son, de un lado, el pedagógico activo del aula, y, por otro, el interactivo con la sociedad, en particular mediante el vínculo del aula con la recepción de los mensajes y las organizaciones e instituciones representativas de la sociedad, encargadas de normalizar modelos de buenas prácticas.

Desde el aula consiste en involucrar al alumnado mediante una pedagogía activa y constructivista, desde la doble perspectiva de analista de discursos audiovisuales y realizador-productor de mensajes alternativos inclusivos. De esta manera el aula deja de ser ese espacio destinado a exhibir productos audiovisuales únicamente como soporte o complemento de los temas previstos en los programas académicos, difundidos mediante la clase magistral y unidireccional, sustentada en la oralidad y textualidad. Pasa a ser el espacio del aprendizaje interactivo destinado a formular la crítica constructiva a los mensajes audiovisuales desde la exclusiva mirada de la cámara. Posicionamos al alumnado en la perspectiva de aprender a pensar de manera audiovisual para acabar produciendo discursos audiovisuales. Para ello, se les enseña el análisis multimodal de los discursos audiovisuales (o su comprensión desde la emisión, producción y recepción) y el desarrollo de la capacidad para la diferenciación de las buenas prácticas inclusivas. Con semejantes procesos edu-investigadores audiovisuales se pretende otorgar al audiovisual el rango de conocimiento epistemológico, teórico y metodológico que debe detentar en la Academia en las sociedades globales actuales en las que el pensamiento tiende a formarse principalmente mediante las interacciones personales y grupales en la red sustentada por el lenguaje audiovisual, como consecuencia de una convergencia mediática que es cada vez más asequible a toda la sociedad, incluidos los colectivos sociales más vulnerables (Orozco 1991, 1994 y 2008, y Castells 1997).

Como el lenguaje y su correspondiente gramática audiovisual son la esencia sobre la que se articula la pedagogía activa en el aula hay que incorporar al proceso edu-investigador elementos narrativos fundamentales correspondientes a la teoría sobre la composición visual, el lenguaje sonoro, el montaje audiovisual y en definitiva la producción de sentidos de los mensajes audiovisuales en general (Berger 1997, 2000 y 2001, Gubern 1987, Martín-Barbero 2001, Millerson 2001) y los audiovisuales publicitarios en particular (Bassat 1994, García y Menéndez 2007, Ricarte 1998). Son, por tanto, procesos eduinvestigadores en los que para producir el spot inclusivo se parte del conocimiento teórico-técnicotecnológico de la cámara (de diferentes tipos: fotográfica, de vídeo, teléfono móvil, etc.) como herramienta principal para comprender sus limitaciones al encuadrar y representar la realidad (Berger 2000 y 2001, Berger y Mohr 1997). Ello permite combinar dicho proceso teórico y hasta epistemológico con el aprendizaje técnico necesario para conocer su manejo y la adaptación a los sucesivos y acelerados cambios tecnológicos, tanto del artilugio en sí como de los programas informáticos y de las aplicaciones de soporte para la edición o montaje de los productos audiovisuales (Morales 2017).

El alumnado debe saber que cada vez se impone más la cultura global de la interconexión social mediatizada por la mirada de la cámara, incorporada al teléfono móvil, mirada que comporta la normalización de nuevas maneras de mostrar la realidad, como la del encuadre vertical en vez del horizontal. Contribuye a ello la mejor manejabilidad del teléfono móvil (Orozco 2008). Reflexiones de este tipo, basadas en hechos contrastados, deben trasladarse al aula para ajustar aún más las propuestas audiovisuales inclusivas formuladas sobre la crianza vulnerable (Lorite 2015, Lorite y Grau 2013). El alumnado ha de saber incorporar a dicha ejecución la argumentación epistemológica, teórica y hasta ética para distinguir y justificar, por ejemplo, el valor de los planos, espaciales y temporales, es decir ese lenguaje elemental de saber distinguir la unidad narrativa de la unidad de trabajo (Millerson 2001) respaldado por el conocimiento de las teorías del montaje (Eisenstein 2001 y Morales 2017). Sobre todo debe distinguir cómo dicho plano espacial, que consiste en encuadrar la realidad, se convierte en temporal mediante el tiempo en continuidad que se le asigna, es parte de un signo que tendrá sentido al ser asociado con el plano anterior y el siguiente. Para realizar un spot de 20 segundos se propone pensar diez tomas como máximo de tal forma que al ser montadas permita obtener el efecto inclusivo deseado. Es ahí donde radica parte importante del trabajo edu-investigador, en descubrir algo tan esencial como es esa "interacción entre dos estímulos (planos-signos) consecutivos" que subraya Gubern (1987: 299). Pero teniendo en cuenta que "cuanto más débil o más hipoformalizada sea la 
estructuración del montaje, tanto más activo y más determinante resultará el efecto Kulechov en la destilación del sentido del sintagma por parte del espectador" (Gubern 1987: 299-300). Es un modelo de investigación audiovisual aplicada que remite continuamente al alumnado a la gramática audiovisual elemental, así como a los autores clásicos. La teoría del montaje, el efecto Kulechov, el cine ruso y detrás de esta propuesta la de Sergei Eisenstein y algunas de sus películas como El acorazado Potenkin y Octubre (Eisenstein 2001).

\section{Sobre la investigación-acción y los decálogos de buenas prácticas}

La investigación audiovisual aplicada tiene sentido vincularla con la investigación-acción. Las ideas que piensa y propone el alumnado para la producción de su publicidad inclusiva sobre la crianza vulnerable tienen en cuenta las recomendaciones acordadas por ciertas instituciones y organizaciones representativas de la sociedad y de los sectores de producción audiovisual implicados, en concreto de las que defienden los intereses de la producción publicitaria y audiovisual como el Consell de l'Audiovisual de Catalunya (CAC 2013), AUTOCONTROL (2011), OBERAXE (Sendín e Izquierdo 2008), Cámara de Comercio Internacional (CCl 2018). A la vez que se les propone colaborar con una investigación como la de la crianza vulnerable y ofrecer ideas para una campaña inclusiva se les propone diseñar su decálogo de buenas prácticas y se les enseña que sin él no es posible realizar ninguna propuesta ni práctica audiovisual. Por tanto, el producto audiovisual inclusivo ideado, diseñado y producido en el aula viene respaldado por los principios que recoge una guía de recomendaciones éticas y estéticas destinada a realizar productos inclusivos a la vez que a cumplir, por supuesto, sus fines comunicativos comerciales, informativos, didácticos y dinamizadores, manteniendo unos estándares mínimos de calidad audiovisual. Para diseñar el decálogo se les recomienda revisar las guías o manuales de los organismos representativos de sectores como el de la publicidad y el del audiovisual, mencionadas anteriormente, así como otras organizaciones como OEA, EAPN o UNICEF. Asimismo, se les incorporan debates con los responsables de ellas en la planificación docente.

Entre las recomendaciones de referencia para abordar de manera inclusiva la crianza vulnerable cabe tener en cuenta las de la Organización de los Estados Americanos (Pedraza 2009) recopiladas en el informe denominado Claves para hablar de la primera infancia en los medios de comunicación (Pedraza 2009). Es posible extraer algunas propuestas en la línea siguiente: "La niñez vulnerada, victimizada, asistencialista, sin identificación y sin voz son algunas de las reiteraciones semánticas y semióticas que día a día se pueden apreciar en los medios de comunicación" (Pedraza 2009: 4). Debido a este tratamiento mediático consideran que: "Para lograr pasar a una niñez sujeto de derechos es necesario contar con periodistas y comunicadores sensibles, con intención de servicio con relación al mundo que los rodea, abarcando su bagaje cultural, contando con su capacidad de cambio como agente transformador de la sociedad" (Pedraza 2009: 4).

El informe de la OEA tiene en cuenta algunas recomendaciones que son fundamentales para que los discursos audiovisuales adecuen los planteamientos teóricos, metodológicos y resultados de las investigaciones científicas a los lenguajes y mensajes de los medios de comunicación e información sin que se diluya su rigor científico. Sugieren adaptar adecuadamente las conclusiones al lenguaje más general y superficial con que puede abordarlo cada medio para llegar a un máximo de audiencia potencial posible. En este sentido sugieren no destacar tan solo los resultados más impactantes y a la postre más sensacionalistas de los resultados de las investigaciones científicas (Pedraza 2009: 10). Son propuestas que han de tener en cuenta las mediatizaciones (definición en la que se adentra más adelante) y adecuar los discursos principalmente textuales de las investigaciones y publicaciones científicas de la Academia en discursos publicitarios audiovisuales que sean capaces de transmitir el mismo nivel de cientificidad. En este sentido recomiendan partir de que "la niñez esté pensada como sujeto de derechos exigibles y no como objeto de compasión y protección" (Pedraza 2009: 10)

Una perspectiva que asume la publicidad de las recomendaciones que vienen haciéndose sobre las imágenes de niños y niñas en los medios de comunicación e información en general y que se tienen en cuenta desde cualquier sector comunicativo son las que pueden encontrarse en la Guía de Periodismo de calidad para la cobertura y promoción de los derechos de niños, niñas y adolescentes (UNICEF 2012), defendida por la UNICEF, en colaboración con la Universidad Católica del Uruguay y la organización Voz y Vos (Agencia de Comunicación por la Infancia y la Adolescencia). Entre las recomendaciones de interés para el alumnado de producción audiovisual publicitaria está la de que hay que "cuidar el uso de 
imágenes (fotos y filmaciones)" (UNICEF 2012: 30).

Son recomendaciones que desde ámbitos como el de la información se vienen revisando continuamente para perfilar un mejor tratamiento mediático de la infancia. En este sentido Milagros Pérez Oliva, durante su etapa como Defensora del Lector del diario El País, publica los Criterios para el tratamiento de las imágenes de menores (Pérez 2010) abordando un tema importante como es el de las imágenes que es conveniente mostrar de los menores. En concreto distingue diferentes situaciones a las que hay que aplicarle diferentes soluciones, pero en general "se aplica el criterio de 'pixelar' el rostro cuando se cree que la foto puede tener efectos negativos sobre el niño". Considera que las imágenes pueden publicarse sin pixelar si tienen el consentimiento de los padres pero que aun así deben pixelarse "incluso cuando los padres dieran el consentimiento, el medio debería igualmente pixelar el rostro, pues se trata de proteger al niño frente a posibles daños a su imagen, en el presente o en el futuro" (Pérez 2010).

La EAPN (European Anti Poverty Network, denominada en España Red Europea de Lucha contra la Pobreza y la Exclusión Social) dispone de la Guía de estilo: pobreza, vulnerabilidad y voluntariado (EAPN 2013) diseñada para "ayudar a los profesionales de la comunicación a ofrecer una información de calidad sobre las personas vulnerables y en situación de pobreza" (EAPN 2013: 1). En ella se advierte que hay que tener mucho cuidado con: "Presentar a las personas en situación de pobreza como objetos de compasión pública, y no como sujetos portadores de derechos" (EAPN 2013: 19). Para evitarlo sugiere cuidar mucho el lenguaje textual (en nuestro caso el que acompaña al visual) y usar antes expresiones como "personas en situación de vulnerabilidad" que "vulnerables" y evitar calificativos como: "pordioseros, marginales, vagabundos, indigentes, mendigos, transeúntes, vagos, abusan del sistema" (EAPN 2013: 20). También consideran que es muy difícil reflejar de manera inclusiva la complejidad de la exclusión social con imágenes pero que en caso de mostrar este tipo de situaciones desde su cotidianidad real apelan a un uso sensibilizador y concienciador. Por ejemplo, sugieren usar primeros planos capaces de mostrar próximas las personas a través de sus gestos y no mostrarlos lejanos y, a ser posible, en grupo junto a otras personas sean o no en situación de exclusión (EAPN 2013: 21). Asimismo, esta guía subraya algo que también nos incumbe para abordar de manera audiovisual e inclusiva las situaciones de la crianza vulnerable, como es la de la mediación inclusiva del rol de las madres. Sobre ello recomiendan tener sumo cuidado con mostrar únicamente a estas mujeres desempeñando solo ciertos roles porque pueden estereotiparlas. Consideran que hay que evitar las "imágenes de pobreza que ahondan en el estereotipo de cronicidad e imposibilidad de salir de ella" (EAPN 2013: 23). Y advierten que las producciones audiovisuales inclusivas deben dar por supuesto que se abordan situaciones muy difíciles, derivadas, por ejemplo, de la extrema pobreza, pero aseguran que son discursos que conviene "recordar que quienes viven en la pobreza están viendo vulnerados sus derechos, pero no por eso dejan de tenerlos" (EAPN 2013: 23). Por ello, consideran lo siguiente: "Es importante mostrar las historias de personas que han conseguido avances, para que la sociedad no tenga una imagen del excluido como un marginado o una carga, ni de la pobreza como una condena perpetua. Las personas pueden salir de la pobreza. $\mathrm{Y}$ es posible vivir en una sociedad sin pobreza" (EAPN 2013: 23).

\section{Algunos conceptos principales de referencia: vulnerabilidad, mediatización y dinamización sociocultural}

Si al alumnado se les pide que viertan ideas sobre la crianza vulnerable es conveniente incorporar desde la pedagogía activa las referencias oportunas para que puedan acotar el tipo de vulnerabilidad que abarca la campaña. Asimismo, se les enseña la perspectiva de metodología multimodal consistente en saber) qué interesa destacar a los que encargan la campaña (se les suele aplicar el calificativo de clientes o anunciantes aunque en este caso se trata de un equipo de investigación de una universidad vinculado con un proyecto competitivo), qué resultados se piensan obtener de ella y cómo se pueden evaluar, qué concepto y estilo publicitarios se defiende y mediante qué medios se piensa difundir. Para resolver estas dudas se van perfilando algunos conceptos como los de crianza vulnerable, mediatización y dinamización sociocultural.

Un concepto amplio de vulnerabilidad que se recomienda tener en cuenta como referencia para las producciones publicitarias audiovisuales inclusivas es el de aporofobia (Cortina 2017). Desde esta perspectiva cualquier persona puede ser vulnerable: "En toda situación, hay personas que están muy bien situadas y otras que no lo están. Por ejemplo, el niño que sufre acoso escolar. Ese pequeño sufre 
'aporofobia'. Hay que tener una sensibilidad muy grande para ver quién es el desprotegido, el vulnerable, porque no en todas las situaciones es evidente" (Europa Press 2017).

Por tanto, podemos partir de la base que al abordar la crianza vulnerable no solo hemos de realizar productos audiovisuales publicitarios pensando en situaciones de pobreza económica, sino también, en todas aquellas que abarcan la desprotección personal.

Desde una perspectiva más amplia también conviene recomendar al alumnado que en su proceso inicial de documentación, destinado a elaborar un guion y de ahí un storyboard que le permita planificar el rodaje del spot, la revisión de otros conceptos que emergen de estudios como los del Análisis urbanístico de barrios vulnerables del Ministerio de Fomento (2018), en los que se profundiza en el concepto de vulnerabilidad urbana. En este caso se acota a partir de la aplicación de una serie de indicadores básicos seleccionados de los Censos de Población y Vivienda y que permiten asociar la vulnerabilidad con ciertas condiciones de vida urbanas además de con la enfermedad y la desprotección, de las ciudades españolas de más de 50.000 habitantes y capitales de provincia (Ministerio de Fomento 2018).

Desde la perspectiva urbana se recomienda revisar propuestas como la de Barcelona Activa. Esta agencia de desarrollo local del ayuntamiento de Barcelona dispone de expertos/as en comunicación de vulnerabilidad, riesgo y crisis. El rol de los/as expertos/as "a cargo de la comunicación en estos casos es poner freno a la crisis mediante el diseño de estrategias de comunicación y la anticipación de los escenarios de crisis para anticipar los riesgos, ganar tiempo, actuar organizadamente, avisar a las personas implicadas, etc.". Desde este planteamiento la vulnerabilidad se asocia con el trabajo de prevención que llevan a cabo las organizaciones y los roles de ciertos expertos/as procedentes del ámbito de la comunicación. Es este sentido se forma al alumnado con el que llevamos a cabo los modelos edu-investigadores en el aula.

Otro concepto de referencia importante a tener en cuenta desde la perspectiva edu-investigadora es el de mediatización. Es posible acotarlo como la manera que tienen los medios de comunicación e información de representar la sociedad y cómo puede influir dicha representación o tratamiento mediático en la forma en la que todos acabemos viendo la sociedad y de relacionarnos e interactuar en ella. Un autor de referencia en ese sentido es Eliseo Verón y sus reflexiones de la mediatización desde la perspectiva semio-antropológica, así como los trabajos en los que abordan las diferencias esenciales entre mediación y mediatización (Verón 2015).

Asimismo, para acotar el concepto de mediatización hay que tener en cuenta a John Thomson (2007) y su teoría sobre los medios de comunicación y la modernidad. En concreto $Y$ se sustituye y) En concreto, cómo estos transmiten contenidos simbólicos que dan lugar a la interacción social al margen de la realidad. Asimismo, es conveniente repescar a autores como Martín-Serrano (1985), que hace años ya advertían sobre la necesidad de profundizar en este tipo de mediaciones de los medios de comunicación. Son aportaciones que permiten abordar la teoría sobre la función dinamizadora sociocultural inclusiva, impartida y trabajada en el aula desde la pedagogía activa (Lorite 2001), en este caso desde la mediatización publicitaria audiovisual inclusiva de la crianza vulnerable. En este sentido cabe considerar que los medios no solo difunden mensajes, también median, mediatizan y dinamizan modelos de comunicación interpersonales, intergrupales e interculturales que pueden ser activos o mecánicos y suscitar la respuesta social inclusiva organizada o desviar el interés únicamente hacia una recepción mecánica y pasiva desde la subjetividad doméstica (Lorite 2015, Orozco 1994, Verón 2004).

\section{Proceso metodológico edu-investigador}

Para vincular al alumnado de Realización Audiovisual Publicitaria con la realización de una campaña sobre crianza vulnerable destinada a un proyecto de investigación se lleva a cabo un proceso metodológico edu-investigador que tiene en cuenta los diferentes criterios que se exponen a continuación:

1) Diseño de un programa de la asignatura que previamente sea aceptado por la coordinación del Grado de Publicidad y Relaciones Públicas con la correspondiente pedagogía activa y constructivista propuesta y que así sea difundido previamente al alumnado al ser publicada la guía docente en Internet.

2) Presentación del programa el primer día de clase con la pedagogía activa y edu-investigadora prevista 
y la explicación sobre cómo es posible aplicarla desde los proyectos publicitarios del alumnado. Se les divide en un total de 9 grupos y les corresponde presentar al final de curso en una página web su proyecto con los trabajos realizados: spots, teletienda, making of y cuaderno de a bordo o memoria cronológica y teórica de curso. El proyecto es obligatorio que parta de un decálogo de buenas prácticas publicitarias inclusivas cuyas recomendaciones principales giran en torno a: a) imagen: uso y valor narrativo principalmente de los planos, movimientos y desplazamientos de la cámara, efectos visuales, escenarios, luz, color y grafismo (Berger 2000 y 2001, Fernández y Martínez 1999, García 2007, Millerson 2001); b) sonido: uso y valor de la banda sonora: voz, música, silencio y efectos sonoros (Blanch y Lázaro 2010, Rodríguez 1998); c) protagonistas: justificación de los cuerpos de los/las protagonistas: género, edad, fenotipo, actitudes e interacciones (Lorite 2021); d) realidad: límites a la representación de la realidad y su recreación mediante la ficción (Martín-Barbero 2001); e) creatividad: límites a ciertos recursos creativos como el humor, las emociones, el dolor, la competencia, etc. (Bassat 1994, Ricarte 1998); f) producción: límites recomendados para los anunciantes o clientes (CCl 2018); g) recepción: límites establecidos pensando en los efectos y procesos de dinamización social del mensaje en las audiencias potenciales (Lorite 2021 y Orozco 1994).

3) A continuación, se introduce el proyecto de investigación sobre crianza vulnerable y se justifica la petición de ideas como ejercicio inicial destinado a "calentar motores" en una asignatura teórico-práctica como esta que vincula docencia con investigación y ambas con la práctica publicitaria profesional. Las ideas se recogen en un formulario con la breve introducción explicativa:

"Si tuviéramos que realizar un spot de 20 segundos de una campaña destinada a sensibilizar sobre la crianza vulnerable o vulnerabilidad infantil, destinada a un organismo público y para ser difundida por internet: 1) ¿Podríamos resumir la idea en una frase?; 2) ¿Sugerimos alguna imagen o imágenes?; 3) ¿Se nos ocurre algún storyboard o asociación posible de esas imágenes?; 4) ¿Cuál sería la banda sonora?; 5) ¿Cuál sería el slogan más apropiado?; 6) ¿Se decantaría por algún concepto o manera de pensar?; 7) ¿Seria de un estilo publicitario determinado?; 8) ¿Se defendería como buena práctica o publicidad inclusiva de calidad desde alguna frase de un decálogo?".

Se vincula este formulario con la investigación, recomendándoles el visionado de videos que resumen los debates organizados desde el proyecto de investigación abordando la crianza vulnerable (2). Asimismo, se les recomienda consultar otros manuales de recomendaciones referenciadas anteriormente y tomar algunos puntos de vista desde lo que, desde la metodología multimodal se denomina "emisión" y que corresponde a las referencias obtenidas del análisis de contenido de una muestra cualitativa extraída y codificada de publicidad institucional sobre la crianza vulnerable desde el proyecto de investigación (Grau 2020).

Para formular las propuestas sobre la crianza vulnerable empiezan a tomar como referencia los mismos elementos que tendrán en cuenta para la realización de las producciones audiovisuales de sus proyectos publicitarios. Estos son: idea, imagen, storyboard, banda sonora, slogan, concepto y estilo publicitarios y decálogo. Son los esenciales también para tener en cuenta desde ese otro punto de vista fundamental de la metodología multimodal como es el de la producción audiovisual publicitaria, practicado en este caso desde la perspectiva profesional o similitud con la realidad productiva del sector.

Se les dio una semana para enviar sus propuestas por email. Finalmente se recogieron un total de 70 formularios de los 72 posibles de alumnado matriculado en la asignatura. Es necesario precisar que se trata de un alumnado cuyas edades oscilan entre $20-21$ años, 64 son mujeres (87\%) y 8 hombres (13\%), el lugar de nacimiento de casi la totalidad es Catalunya (salvo algún Erasmus) y su lengua materna es principalmente el catalán.

Las propuestas del alumnado son tenidas en cuenta por el profesorado desde el proceso eduinvestigador y la pedagogía activa que permite tomar el ejemplo como punto de partida para desarrollar sus proyectos publicitarios. Pero también son ideas que permiten ajustar mejor la campaña definitiva prevista en el proyecto de investigación puesto que es el mismo profesorado el encargado de coordinarla y realizarla (el profesorado que imparte la asignatura está compuesto por Nicolás Lorite García como responsable de la coordinación, Joan Riedweg y Joaquim Crespo). Es, por tanto, otro de los vínculos edu-investigadores: el profesorado incorpora la investigación al aula, implica al alumnado en ella desde la doble perspectiva docente e investigadora, pero también se encarga de realizar la propuesta audiovisual publicitaria definitiva. 
Desde la multimodalidad metodológica conviene tener en cuenta además las ideas o propuestas que vienen de los clientes. Por lo general estas son las que suelen imponerse y las que determinan los contenidos y el tratamiento final del anuncio. En este caso no se llega a dichas determinaciones propias del mercado publicitario, pero sí permite calibrar algunas diferencias y similitudes entre lo que puede interesar al equipo de investigación del proyecto, que es el que encarga la campaña con el objetivo de mostrarla como un resultado más de la investigación, en este caso como buena práctica inclusiva, y lo que propondría el equipo de creativas/os o alumnado, e, incluso, lo que considera oportuno el equipo de producción de la campaña definitiva formado por el profesorado. Para tener en cuenta esta perspectiva de los que encargan la campaña, se debatieron y sintetizaron, algunas propuestas, haciendo uso de un formulario en el que se tienen en cuenta algunas cuestiones como qué se quiere contar, si se pretende hacer una reflexión del problema a nivel local o global, desde donde se posiciona, construye y representa la mirada, si se destina a los niños del Tercer Mundo o a los de Catalunya nada más, ¿quién encargaría y difundiría la campaña y con qué objetivos?, ¿a quién va destinada y que efectos se pretenden conseguir?, ¿qué proceso de producción y realización conviene aplicar?, ¿cómo recogemos el proceso de elaboración de la campaña para su uso didáctico y divulgativo?, ¿qué slogan o frases pueden tener más fuerza o impacto?

\section{Resultados}

\subsection{Ideas}

El total de 70 ideas del alumnado para la producción audiovisual de una campaña sobre la crianza vulnerable es posible agruparlas de acuerdo a las siguientes propuestas generales:

1) Ideas destinadas a abordar diferentes vulnerabilidades sociológicas y socioculturales de la crianza: "ayudar a los niños/as autistas en su proceso de integrarse en sociedad, sobre todo en la escuela y en casa"; "Marc se conecta a su clase virtual, donde descubre que a causa de la brecha digital no se siente uno más de la clase"; "realizar una campaña dirigida a evitar el acoso escolar, dirigido al acosador para que empatice con la situación de su víctima"; "la importancia de la integración de alumnado de centros de acogida en las escuelas"; "un spot donde aparezcan niños de diferentes etnias realizando actividades cotidianas"; "el objetivo es demostrar el contraste que existe entre lo que los niños, niñas y jóvenes que viven procesos migratorios esperan del país al que llegan, y la realidad a la que se enfrentan una vez lo hacen"; "he optado por crear una campaña de concienciación sobre los niños y niñas vulnerables que nacen y crecen en familias monoparentales, estas muchas veces se encuentran en situaciones precarias y/o de pobreza, ya sea por la pérdida de empleo, o por otro tipo de recortes, por ese motivo, estos niños y niñas crecen sin tener la posibilidad de formarse como les gustaría académicamente y reciben un estilo de vida que no va acorde con el bienestar que se merecen, me he inspirado en un estudio realizado por Save the Children en el año 2018 que trata sobre el coste de la crianza en España"; "los estereotipos como un límite al desarrollo de los más pequeños, hace referencia a los estereotipos de género en la publicidad infantil"; "menores con identidad transgénero, la transexualidad infantil".

2) Ideas desde la mirada del niño, desde sus señales, signos, juegos, opiniones, experiencias: "Teniendo en cuenta que no existe una mirada más honesta que la de un niño, el spot empezaría con la mirada de un niño pequeño mirando a la cámara fijamente, mediante un zoom o un travelling out la cámara se irá alejando hasta que veamos la cara del niño en su totalidad y contextualicemos que se encuentra en una casa de pocos recursos. La idea es transmitir al espectador que sí tiene alrededor o conoce a algún niño en situación de vulnerabilidad, pida ayuda"; "mostrar diferentes señales que pueden dar los infantes en situación de vulnerabilidad en su día a día como, por ejemplo, un dibujo que hace en la escuela, de su familia"; "la tristeza e inocencia a partir de la expresión de un niño/a"; "los niños tienen opiniones y debemos escucharlos y aprender"; "la campaña propuesta busca un enfoque en primera persona, pues los niños y niñas que están en esta situación son los que mejor nos pueden mostrar su propia visión y experiencia de esta"; "representación del papel de los padres en los niños viéndolos desde los ojos de sus hijos".

3) Ideas sobre cómo la convivencia familiar con padres enfrentados, alcohólicos, drogadictos, maltratadores, puede derivar en malas conductas, violencia, marginación y determinar el futuro del niño: "los niños que lo están pasando mal ahora, también lo van a pasar mal en un futuro y solo tú puedes ayudar"; "el tipo de infancia que vivas determinará el tipo de futuro que tendrás"; "la infancia es una etapa 
de la vida que no se puede repetir, ni volver a ella y por lo tanto la infancia que se vive es la que perdura y modela al niño o niña que la vive"; "el maltrato físico en la infancia hace que se normalice la violencia en la adultez"; "la idea sería transmitir que los padres, hermanos, familia, en definitiva, son el ejemplo, ese héroe al que aspiran ser de mayor, pero todo héroe que utiliza mal sus poderes acaba obteniendo malos resultados, y en este caso no podemos permitirnos eso"; "el punto de vista de diversos niños y niñas que viven situaciones de crianza vulnerable en casa como por ejemplo vivir con padres alcohólicos y como lo ven los niños o niñas"; "la drogadicción de los padres es un problema que afecta también a los menores a su cargo", "se trata de la historia de un niño/a que sufre violencia psicológica por parte de sus padres por la separación entre ambos".

4) Ideas para actuar, concienciar, resaltar la desigualdad, ayudar, solidarizarse, implicarse, cuidar, atender la crianza vulnerable y mostrarla tal cual es: "es importante concienciar a la población de que no debe permitir que ningún/a niño/a sufra esta situación y se debe actuar para ayudarles"; "spot emotivo (...) que apelara a la solidaridad de la sociedad y movilizara a la acción social para que se pueda dar respuesta a esta población vulnerable"; "juntos podemos luchar contra las desigualdades para conseguir un mundo mejor y más justo con igualdad de oportunidades"; "crecer de una forma feliz e igualitaria debería ser una obligación no una oportunidad"; "cuida de lo más frágil porque se hará fuerte, y, cuidará de ti, con esta frase se pretende plasmar la importancia de cuidar de los seres más débiles, porque, estos luego crecerán y serán el futuro"; "visibilízalo para erradicarlo (...) debemos de hablar sin tapujos y no apartarlo como si fuese un tabú".

\subsection{Imagen}

Al alumnado se le solicitó además que propusieran imágenes (dibujadas, fotografiadas o extraídas de un banco de imágenes gratis, destinadas a la realización práctica de su idea), así como un storyboard o asociación narrativa de las diferentes imágenes seleccionadas. Tanto en un caso como el otro se constata que:

1) En todas las propuestas los niños/as son los protagonistas principales de la acción.

2) En la mayoría se muestran rostros tristes y una parte de ellos asociados con las situaciones personales, conflictivas y de pobreza extrema que sintetizan en sus ideas.

3) Solo algunas propuestas derivan hacia una producción audiovisual de calidad capaz de mostrar la doble cara negativa y positiva de la vulnerabilidad y estructurar mensajes objetivos que oscilan de lo negativo a lo positivo o viceversa.

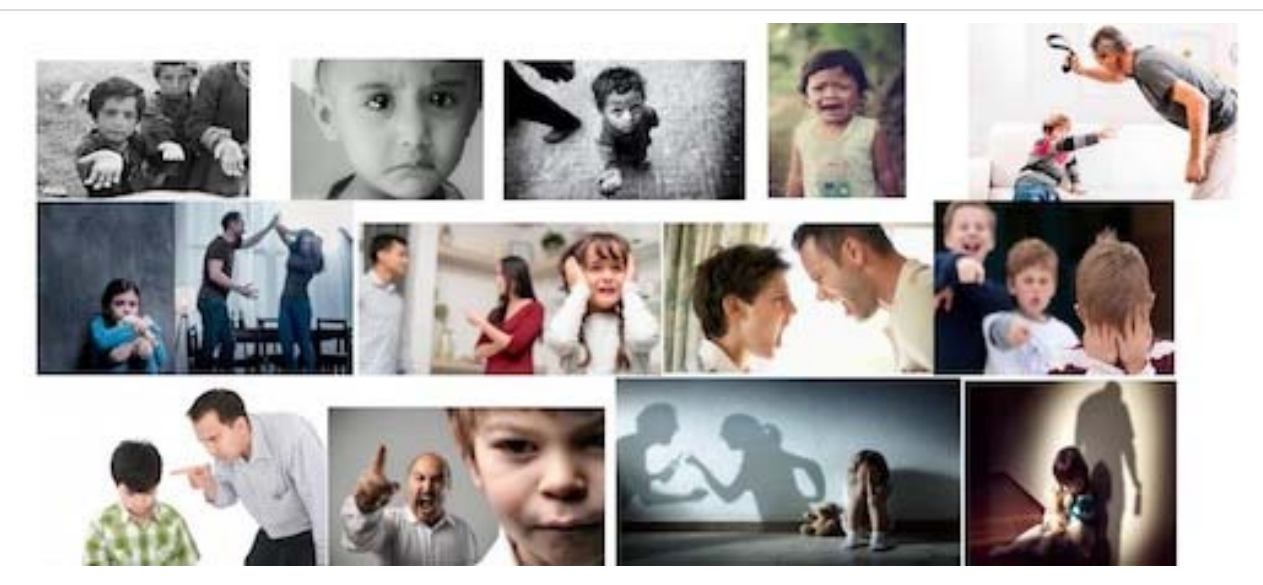

Imagen 1. Imágenes seleccionadas por el alumnado para la realización de un spot de 20 " sobre la crianza vulnerable.

\subsection{Storyboard}

Una de las perspectivas tenidas en cuenta desde los storyboards es la del contraste de dos mundos, como puede verse en el ejemplo siguiente (imagen 3) a partir de una primera idea visual (imagen 2). 


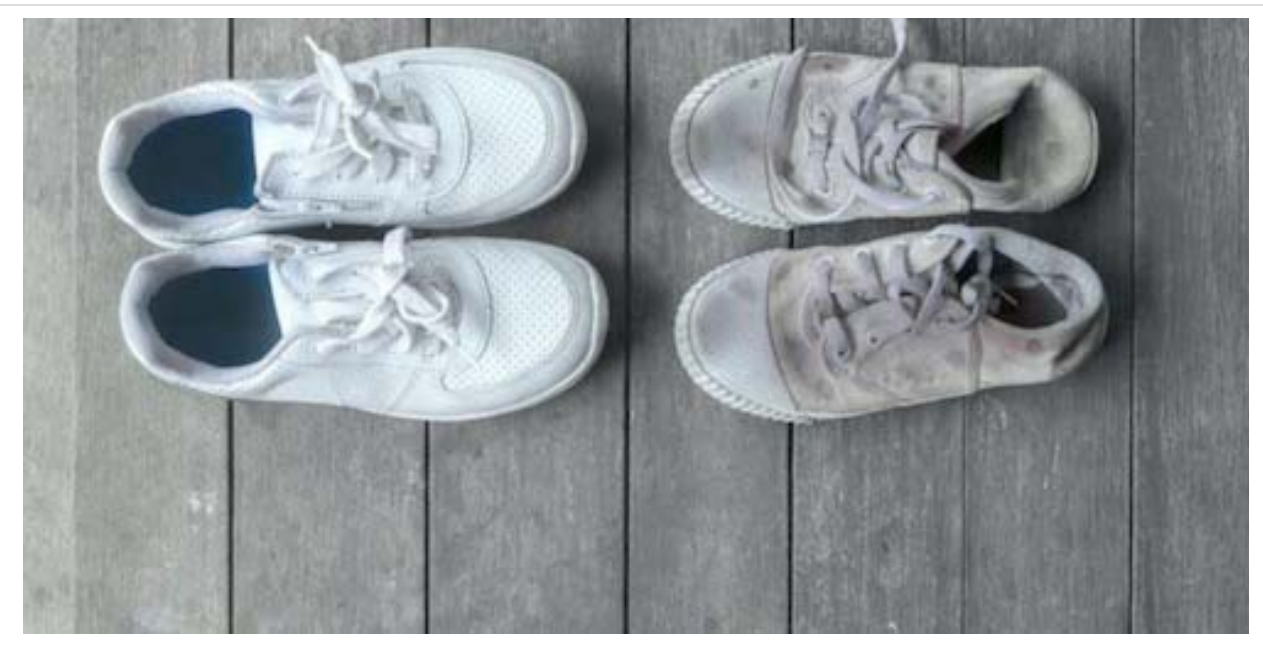

Imagen 2. Imagen con que se asocia la infancia vulnerable.

Un niño subiendo una pequeña montaña
Otro niño diferente caminando sobre un camino
fäil y asfaltado.
Los niños se encuentran en su camino y siguen
caminando juntos.
Los dos niños se encuentran ante un cartel en una
bifurcación.
En el cartel se ve que las personas que tengan
unos buenos zapatos deben ir por un camino y los
que tienen unos zapatos rotos o más desgastados,
deben ir hacia el otro camino.
Los niños se tienen que separar porque sus zapatos
son diferentes, ya que uno ha tenido que subir una
montaña y el otro ha ido por un camino más fäcil
y, por lo tanto, sus zapatos están en mejor estado.

Imagen 3. Storyboard para un spot de 20 " sobre la crianza vulnerable.

\subsection{Banda sonora (música, voz, silencio y efectos)}

Al solicitarles ideas para la banda sonora (voz, música, efectos y silencio) que acompañaría al spot de 20 segundos se constata que:

1) Una mayoría la asocia únicamente con la música. Muy pocas propuestas acuden al uso de los otros elementos de la banda sonora. Las músicas seleccionadas son de una sola melodía lenta, triste, calmada, lineal, seria, emocional: "melodía lenta y triste, para empatizar con el protagonista del spot"; "música de fondo emocional y dramática"; "lenta y calmada, bastante lineal"; "música seria"; "música emocional". O bien también una sola música pero que pretende otorgarle al relato efectos de intriga, 
suspense: "música inquietante, que sea agobiante para el que la escuche, de manera que se ponga en la piel del niño que no puede escapar de todo aquello que vive"; "de suspense, pero sin ser de terror"; "movida y caótica para reflejar la situación"; "a medida que las imágenes se van oscureciendo, se va desvaneciendo la música y va cogiendo fuerza una canción que transmita ansiedad, tensión y angustia".

2) Algunas propuestas acuden a canciones de niños, interpretadas, incluso por niños: "canción alegre interpretada por niños"; "canción infantil pero ralentizada al máximo para que vaya muy lenta y que sea más emotiva"; "nana de niños pequeños con un punto tenebroso". Sin lugar a duda, el piano es el instrumento idóneo para algunas: "melodía a piano muy emotiva"; "piano triste, con un ritmo lento, pero con fuerza"; "una canción de piano, emotiva pero no muy lenta para que fuese acorde con la consecución rápida de cambio de imágenes".

3) En algunas propuestas se reflexiona sobre la incorporación de ciertos elementos sonoros, como por ejemplo: a) la de incorporar canciones con o sin letra: "instrumental sin mucha letra", "música que refleje desconcierto y soledad sin letra", "música triste (instrumental, sin letra)"; b) el tono de la música: "lenta con tonos que tiendan a agudos o medios no graves y que remarcase muy bien ciertos puntos para poder aportar énfasis"; c) la incorporación del silencio: "el silencio juega un papel fundamental, ya que hace reflexionar al espectador", "cualquier música instrumental que a medida que avanza la canción se vuelve más intensa y en la parte final silencio para dramatizar el concepto y llamar la atención"; d) solo una propuesta piensa en incorporar algún efecto sonoro: "el sonido de la televisión estaría de fondo, se oiría un programa clásico americano con risas enlatadas"; e) incluso hay propuestas que se decantan por el uso exclusivo del sonido ambiente y de las voces propias de dicha escena sin contar con ningún elemento sonoro más: "solo se escucha el sonido ambiente de la escena, luego se oye la frase del padre, finalmente, la voz en off", "dejar que se escuche de manera limpia al niño gruñendo, el ruido de las cadenas y al narrador", "que se escuchara perfectamente el sollozo del niño", "risas y sonidos de ambiente que sugieran la palabra familiaridad"; f) y algunas propuestas acuden únicamente a músicas de películas o canciones conocidas como: Blackbird de The Beatles, We are the world cantado por niños, Imagine de John Lennon, Born This Way de Lady Gaga, Family of the year de Hero o las músicas de las películas El último mohicano, The Gladiator o Forrest Gump.

4) También se observa alguna propuesta que tiene en cuenta un tratamiento sonoro musical destinado a hacer espacial énfasis sobre un principio feliz con un final triste, o bien a combinar adecuadamente diferentes tipos de música en función del momento narrativo: "al principio triste al ver imágenes de un niño autista sintiéndose solo y después optimista y feliz mientras sus compañeros de clase se acercan a él y le piden que jueguen juntos"; "al principio sería una música triste, pero, cuando aparecen las manos, la música cambia a un estilo más alegre y esperanzador"; "un poco alegre al principio y luego se volvería más lenta y triste con un toque melancólico"; "lenta y tranquila con algún momento de tensión"; "de una melodía simpática e infantil, a una más seria y adulta"; "inicialmente, una música alegre y animada que acentúe el estado utópico en el que desearía vivir el o la protagonista; y al cambiar de perspectiva (a una más centrada en la realidad que se vive en España), música instrumental y de carácter más dramática para hacer especial énfasis en la gravedad del asunto (EL RACISMO)".

\subsection{Estilo publicitario}

Parte importante de las propuestas derivan hacia el estilo que Lluís Bassat (1994) denomina "impacto emocional" y que va destinado a establecer vínculos emocionales con los receptores de los mensajes y que es uno de "los caminos creativos que más ha contribuido a construir la imagen de grandes marcas" (Bassat 1994). Entre las propuestas destacan las siguientes: "emocional que quiere hacer reflexionar al espectador y ponerle los sentimientos a flor de piel"; "emocional, ya que intentamos apelar la parte más emotiva y humana del receptor"; "emocional, ya que apela unos sentimientos, quiere despertar en el oyente una sensibilización respecto al problema"; "impacto emocional, al final lo que busca es generar esa angustia y/o esa emoción que a veces no nos gusta de la soledad". En algún caso se combina el impacto emocional con otro de los estilos que tiene en cuenta Bassat (1994), el comparativo: "sería tanto publicidad emocional, ya que lo que busca es la compasión con la crianza vulnerable, como comparativa, atendiendo a que el principio del spot muestra una infancia totalmente diferente a la que protagoniza el final de la pieza".

Algunas propuestas consideran que el spot ha de ser concienciador y tener una perspectiva realista, objetiva, pedagógica o educativa: "concienciador y tono serio para buscar la empatía del público"; "concienciador, propio de una ONG"; "estilo serio de concienciación, pero también de empoderamiento a 
la población para mostrar que esta tiene la capacidad de aportar su granito de arena para solucionar el problema"; "de carácter social, para conseguir con ello cambiar el estilo de anuncios que existen hasta la fecha con niñes"; "realista y objetivo (por lo tanto, sin toques humorísticos), que consiga que la gente crea aquello que escucha y ve"; "realista, no sería un enfoque ni positivo ni negativo, simplemente mostrar una realidad". Algunas propuestas combina todo ello con el impacto emocional: "serio, pedagógico, emocional", "emocional, social, de concienciación"; "publicidad emocional y educativa a la vez".

Cinco propuestas prefieren el storytelling o manera de narrar historias cotidianas desde el punto de vista de la misma cotidianidad social: "storytelling narrando una historia pero con final abierto, ya que el espectador puede decidir el futuro que tendrán esos niños, en sus manos están contribuir y ayudarles"; storytelling que te explica la historia de un niño que en vez de tener una infancia corriente y un padre que le lee cuentos por la noche, tiene un padre que abusa de él por las noches"; "técnica del storytelling, pero también sería conveniente hacer ciertas yuxtaposiciones comparativas para resaltar las dos realidades de la vida".

\subsection{Decálogo}

De acuerdo con la metodología y pedagogía aplicadas el spot propuesto por el alumnado ha de basarse en algunos principios o recomendaciones para que pueda ser considerado una buena práctica o una publicidad audiovisual inclusiva. Una primera observación es que más de la mitad no entienden bien la función ética y estética del decálogo. En concreto $12(17,1 \%)$ no responden o no entienden bien la pregunta, que sumados/as a los $15(21,4 \%)$ que dan un tipo de explicación que no tiene nada que ver con lo que se solicita en la pregunta y a los/as 11 (15,7\%) que solo responden afirmando que lo usaría, pero sin ninguna frase, permite constatar que un total de 38 alumnos/as $(52,3 \%)$ no entienden bien la función del decálogo. Dicho desconocimiento suele ser habitual al inicio del curso.

No obstante, ese desconocimiento contrasta con algunas reflexiones al respecto muy bien argumentadas y documentadas como las dos siguientes: "sí que correspondería a una buena práctica o publicidad inclusiva, aquí tenemos algunas frases de decálogos que lo refuerzan: a) reflejar la realidad puede ayudar a mejorar la imagen de la marca y a identificarse con el producto o servicio (Decálogo de 2019 elaborado por el Colegio de Publicitarios y Relaciones Públicas de Cataluña, Consejo del Audiovisual de Cataluña y el Instituto Catalán de las Mujeres), b) representemos a las personas como sujetos, no como objetos. (Decálogo del Circulo Uruguayo de la Publicidad), c) asumimos que la ciudadanía es diversa (Decálogo del Departamento de Desarrollo Rural, Medioambiental y Administración Local del Gobierno de Navarra)"; "según el decálogo sobre Publicidad e Infancia creado por UNICEF y el Círculo Uruguayo de la Publicidad debemos tener en cuenta lo siguiente: a) la utilización de niños, niñas y adolescentes en publicidad debe ser extremadamente cuidada y respetar las particularidades de cada etapa de su desarrollo, b) no podrán aparecer niños, niñas o adolescentes en publicidades que promocionen bebidas alcohólicas, cigarrillos o cualquier producto perjudicial para la salud, o que atenten contra su dignidad o integridad, c) en la publicidad de productos no destinados a ser utilizados por niños no deberán ser protagonizados por niños o niñas, d) cuando las publicidades utilicen niños o adolescentes ellos no podrán estar en actitudes propias del mundo adulto, sexualizados o protagonizar situaciones que puedan resultar perjudiciales para su bienestar físico o mental".

Asimismo, también se recoge alguna propuesta que sugiere conocer la realidad antes de cerrar las propuestas del decálogo: "esta campaña me gustaría que se consultara antes con personas que estén en esta situación para que valorasen si hace justicia a la realidad o no y en qué se podría mejorar, ya que no hay que olvidar que, por mucho que investiguemos, nunca llegaremos a entenderlo $100 \%$ sin haberlo vivido. En el decálogo, pues, se pondría como requisito el trabajar toda la realización con alguien que haya vivido esta situación y también hacer una prueba piloto con personas que también lo hayan vivido para asegurarnos que mostramos su realidad como es y no como la vemos nosotros desde un punto de vista exterior".

También se observa un interés por las diversidades socioculturales, étnicas, funcionales, de género, de orientación sexual, de nuevas relaciones familiares: "sería una campaña de publicidad inclusiva porque aparecerían casos de diversos niños/as con diversidad funcional, de etnias distintas"; "pretendería que no hubiese diferencias raciales, que no se menosprecie o se cree ningún juicio de valor sobre la procedencia de los componentes de la familia...". 


\subsection{Discusión}

Para que la mirada de la cámara sea inclusiva es necesario determinar qué se puede mostrar, a quién nos dirigimos y qué efectos dinamizadores socioculturales deseamos suscitar en la población. Estas son algunas de las reflexiones que se incorporan al aula desde la primera clase de Realización Audiovisual Publicitaria del Grado de Publicidad y Relaciones Públicas. En concreto, desde una pedagogía activa y modelos de investigación audiovisual aplicada e investigación-acción que pretenden enseñar al alumnado a "escribir" discursos audiovisuales inclusivos, a realizar la buena práctica, a partir de los elementos esenciales de la gramática audiovisual (Berger 1997, 2000 y 2001, Gubern 1987, Eisenstein 2001) y a vincular dichos procesos formativos con la investigación interdisciplinar competitiva y las guías y manuales de las organizaciones e instituciones encargadas de cuidar la producción de buenas prácticas publicitarias.

Por eso se les pide una idea por escrito, pero a continuación se les incita a diseñar, fotografiar o encontrar una imagen con la que asociar la idea. Y a partir de ahí se les propone que piensen algunas imágenes más y las organicen en un storyboard (Hart 2001) o primer montaje estructurado con ellas. Pero a la vez se les solicita que tengan en cuenta un estilo publicitario (se inclinan por el impacto emocional) (Bassat 1994). Y se les acaba subrayando que antes de dar el paso siguiente, destinado a guionizar, grabar y editar el producto audiovisual (Millerson 2001, Morales 2017) tengan en cuenta los principios éticos y estéticos en los que se basan, sintetizados en un decálogo.

El decálogo va a determinar qué planos, qué protagonistas, qué banda sonora, qué efectos, qué grafismo, entre otros elementos de la gramática audiovisual, tienen en cuenta, para realizar su producto audiovisual publicitario. Pero para que dichas decisiones determinen la realización de un discurso inclusivo no solo han de elegir una imagen, sino saber distinguir su valor narrativo al encuadrarla y sobre todo al asociarla con otras mediante el montaje. Hay que determinar en el decálogo qué planos y asociación de planos es la oportuna para representar de la manera más adecuada la crianza vulnerable. De ahí la necesidad de incorporar al aula las diferentes propuestas que se recogen en este texto desde el CAC (2013), CCI (2018), EAPN (2013) o UNICEF (2012).

Finalmente, algo importante que hay que resaltar: mientras se lleva a cabo este ejercicio eduinvestigador, intentando encontrar la mirada inclusiva de la cámara, se fomenta la concienciación social, crítica y solidaria, de los futuros/as publicitarios/as en torno a temas tan sumamente complejos como el de la crianza vulnerable.

\section{Notas}

Este artículo recoge algunos resultados del proyecto de investigación Crianza, desamparo $y$ vulnerabilidad sociocultural. Análisis situacional y propuestas de intervención (CSO2017-83101-C2-1-R), codirigido por el Dr. Jorge Grau Rebollo y la Dra. Anna Piella Vila, y financiado por el Ministerio de Ciencia, Innovación y Universidades.

1. Proyecto de investigación Crianza, desamparo y vulnerabilidad sociocultural. Análisis situacional y propuestas de intervención (CSO2017-83101-C2-1-R), codirigido por el Dr. Jorge Grau Rebollo y la Dra. Anna Piella Vila, y financiado por el Ministerio de Ciencia, Innovación y Universidades, en el que participa Nicolás Lorite García, como director del Migracom-UAB e investigador audiovisual del Departamento de Publicidad, Relaciones Públicas y Comunicación Audiovisual de las UAB.

2. Jornada llevaba a cabo durante las 3 horas de duración de la segunda clase de la asignatura Realización Audiovisual Publicitaria de $3^{\circ}$ del Grado de Publicidad y Relaciones Públicas de la Universitat Autònoma de Barcelona, del curso 2019-20. Debate destinado a abordar la producción de buenas prácticas inclusivas. Contó con la participación de Carme Figueras, consellera del Consell de l'Audiovisual de Catalunya (CAC), Richard Wafelfield, director creativo de Publicitarios Implicados, y el profesorado de la asignatura: Joan Riedweg, Joaquim Crespo y Nicolás Lorite García. Ver resumen en video de la jornada en Youtube y Vimeo: https://www.youtube.com/watch?v=17Dh-95sYbM y https: //vimeo.com/397460938 


\section{Bibliografía}

Achutti, Luiz Eduardo

1997 Fotoetnografía. Porto Alegre, Tomo Editorial Ltda e Livraria Palmarica.

Aguaded, J. Ignacio

2012 "La competencia mediática, una acción educativa inaplazable", Comunicar, n 39: 7-8.

DOI: 10.3916/C39-2012-01-01.

Aparici, Roberto

2011 "Educomunicación: Más allá del 2.0", Nómadas, n 35: 264-266.

AUTOCONTROL

2011 Código de conducta publicitaria. https://www.autocontrol.es/codigos-de-conducta/

[Consultado: 25 de marzo de 2021]

Barcelona Activa

https://www.barcelonactiva.cat/ [Consultado: 25 de marzo de 2021]

Barroso, Jaime

1989 Introducción a la realización televisiva. Madrid, IORTV.

Bassat, Lluís

1994 El libro rojo de la publicidad. Madrid, Debolsillo.

Berger, John

2000 Modos de Ver. Barcelona, Gustavo Gili.

2001 Mirar. Barcelona, Gustavo Gili.

Berger, John (y Jean Mohr)

1997 Otra manera de contar. Murcia, Mestizo A. C.

Berger, Peter (y Thomas Luckmann)

2008 La construcción social de la realidad. Madrid, Amorrortu.

Blanch Margarida (y Patricia Lázaro)

2010 Aula de locución. Madrid, Cátedra.

Buxó, María Jesús (y Jesús María De Miguel) (ed.)

1998 De la investigación audiovisual. Fotografia, cine, video, televisión. Barcelona, Proyecto A Ediciones.

Cámara de Comercio Internacional $(\mathrm{CCl})$

2018 Código de Publicidad y de Comunicaciones de Mercadeo. París, International Chamber of Commerce (ICC). https://www.autocontrol.es/2018/10/05/publicada-la-nueva-version-revisada-del-codigopracticas-publicitarias-la-camara-comercio-internacional/ [Consultado: 25 de marzo de 2021]

Castells, Manuel

1997 La era de la información. Economía, sociedad y cultura. Madrid, Alianza Editorial.

Coll, César (y otros)

1999 El constructivismo en el aula. Barcelona, Biblioteca de Aula.

Consell de l'Audiovisual de Catalunya (CAC)

2013 El discurs mediàtic sobre la immigració a Catalunya. Reflexións per a la consecució d'un llenguatge inclusiu. Barcelona, Mesa per la Diversitat en l'Audiovisual, CAC.

https://www.mesadiversitat.cat/materials/discurs-mediatic-la-immigracio-catalunya-reflexions-la-

consecucio-dun-Ilenguatge-inclusiu [Consultado: 25 de marzo de 2021]

Cortina, Adela

2017 Aporofobia, el rechazo al pobre. Un desafío para la democracia. Barcelona, Paidós.

EAPN, European Anti Poverty Network 
2013 Guía de estilo: pobreza, vulnerabilidad y voluntariado.

https://www.eapn.es/publicaciones/140/guia-de-estilo-para-periodistas-pobreza-vulnerabilidad-

y-voluntariado [Consultado: 25 de marzo de 2021]

Echevarría, Javier

1995 Cosmopolitas domésticos. Barcelona, Anagrama.

Eisenstein, Sergei M.

2001 Hacia una teoría del montaje, vol. 2. Barcelona, Paidós.

Europa Press

2017 "No es xenofobía, es aporofobía (rechazo al pobre)", Europapress (Madrid), 7 de agosto.

https://www.europapress.es/epsocial/derechos-humanos/noticia-no-xenofobia-aporofobia-rechazo-pobre-

20170514114457.html [Consultado: 25 de marzo de 2021]

Fernández Diez, Federico (y José Martínez Abadía)

1999 Manual básico de lenguaje y narrativa audiovisual. Barcelona, Paidós.

Ferrés, Joan

1994 Televisión y educación. Barcelona, Paidós.

2005 Com veure la TV? Barcelona, Consell de l'Audiovisual de Catalunya.

Ferrés, Joan (y Alejandro Piscitelli)

2012 "La competencia mediática: propuesta articulada de dimensiones e indicadores", Comunicar (Huelva), n 38: 75-82. DOI: 10.3916/C38-2012-02-08.

García, María Luisa (y Tania Menéndez)

2007 Fundamentos de la realización publicitaria. Madrid, Fragua.

Grau Rebollo, Jordi

2020 "El papel de la publicidad social en el abordaje de la vulnerabilidad sociocultural. Panorama y reflexiones a propósito del caso español", Intexto (Porto Alegre), UFRGS, $\mathrm{n}^{\circ}$ 49: 18-40, DOI: http://dx.doi.org/10.19132/1807-8583202049.18-40 35.

Gubern, Roman

1987 El simio informatizado. Madrid, Fundesco, $3^{\text {a }}$ edición.

Hart, John

2001 La técnica del Storyboard. IORTV. Madrid.

Lorite, Nicolás

2001 "Una pedagogía activa del lenguaje televisivo para los comunicadores del futuro", Comunicar, $\mathrm{n}^{\circ} 11$ : 138-143. https://www.revistacomunicar.com/ojs/index.php/comunicar/article/view/C17-2001-21

[Consultado: 14 de junio de 2021]

2015 "La cámara como principal herramienta para la investigación audiovisual de los procesos de dinamización intercultural mediatizados", Intexto (Porto Alegre), UFRGS, $n^{\circ}$ 34: 178-199. DOI: http://dx.doi.org/10.19132/1807-8583201534.178-199

2021 "Publicidad, diversidad fenotípica y dinamización intercultural en Cataluña en tiepos de crisis y cambios", Cuadernos.info, n 48, 139-165. DOI: https://doi.org/10.7764/cdi.48.27671.

Lorite, Nicolás (y Jordi Grau)

2013 "Investigación audiovisual de las migraciones y el tratamiento de la diversidad en los medios de comunicación: un estudio de caso", en Antolín Granados (ed.), Las representaciones de las migraciones en los medios de comunicación. Madrid: Trotta: 139-155. https://ddd.uab.cat/record/188368/ [Consultado: 14 de junio de 2021]

Maldonado, Alberto Efendy

2013 "A perspectiva transmetodológica na conjuntura de mudança civilizadora em inícios do século XX", en Alberto Efendy Maldonado, Jiani Bonin y Nisia Martin do Rosário (org.), Perspectivas metodológicas em comunicação; novos desafios na prática investigativa. Salamanca, Comunicación Social Ediciones y Publicaciones, vol. 1: 31-57. 
2018 "Articulaciones transmetodológicas para una epistemología latinoamericana en comunicación", Revista Latinoamericana de Ciencias de la Comunicación (São Paulo) vol. 15, nº 28: 62-71.

Martín-Barbero, Jesús (y Germán Rey)

2001 Os exercícios do ver, hegemonia audiovisual e ficção televisiva. São Paulo, Ed. Senac.

Martín-Serrano, Manuel

1985 "La mediación de los medios", en Miquel de Moragas, Sociología de comunicación de masas.

Barcelona, Gustavo Gili.

McQuail, Denis

1969 Sociología de los medios masivos de comunicación. Buenos Aires, Paidós.

Millerson, Gerard

2001 Técnicas de realización y producción en TV. IORTV, Madrid.

Ministerio de Fomento

2018 Análisis urbanístico de barrios vulnerables. https://tinyurl.com/5e3rk954

[Consultado: 25 de marzo de 2021]

2018 Observatorio de la Vulnerabilidad Urbana. https://tinyurl.com/y్jkpㅁ9

[Consultado: 25 de marzo de 2021]

Morales, Fernando

2017 Editing and Montage in International Film and Video: Theory and Technique. London, Focal Press-

Rouledge/Taylor and Francis.

Negroponte, Nicholas

1995 El mundo digital. Barcelona, Ediciones B.

Orozco, Guillermo

1991 Recepción televisiva, tres aproximaciones y una razón para su estudio, Cuadernos del PROIICOM, Universidade Iberoamericana, México D. F., $\mathrm{n}^{\circ} 2$.

1994 "Televidencia: perspectivas para el análisis de los procesos de recepción televisiva", Cuadernos de comunicación y prácticas sociales (México D. F.), Universidad Iberoamericana, Programa Institucional de Investigación en Comunicación y Prácticas Sociales, $n^{\circ} 6$.

2008 "Audiencias y pantallas en América”, Comunicar (Huelva), nº 30: 10-30.

Pedraza, Diana Mireya

2009 Claves para hablar de la primera infancia en los medios de comunicación. Whashington, D.C., Organización de Estados Américanos (OEA).

Pérez Oliva, Milagros

2010 "Criterios para el tratamiento de las imágenes de menores", El País (Madrid), 12 de julio.

https://blogs.elpais.com/defensora-del-lector/2010/07/criterios-para-el-tratamiento-de-las-

im\%C3\%A1genes-de-menores-.html [Consultado: 25 de marzo de 2021]

Pérez Tornero, José Manuel

2000 Comunicación y educación en la sociedad de la información. Barcelona. Paidós.

Ricarte, José María

1998 Creatividad y comunicación persuasiva. Bellaterra, Serveis de Publicacions de la Universitat Autònoma de Barcelona.

Rodríguez Bravo, Ángel

1998 La dimensión sonora del lenguaje audiovisual. Barcelona, Paidós.

Sendín, José Carlos (y Patricia Izquierdo)

2008 Guía práctica para los profesionales de los medios de comunicación. Tratamiento informativo de la inmigración. Madrid, OBERAXE.

https://www.inclusion.gob.es/oberaxe/es/publicaciones/documentos/documento 0066.htm 
[Consultado: 25 de marzo de 2021].

Thompson, John

2007 Los media y la modernidad: Una teoría de los medios de comunicación. Barcelona, Paidós.

\section{UNICEF}

2012 Guía de periodismo de calidad para la cobertura y promoción de los derechos de niños, niñas y adolescentes. Montevideo, Voz y Vos. Agencia de Comunicación por la Infancia y la Adolescencia, UNICEF Uruguay, Universidad Católica del Uruguay.

https://www.observatoriodelainfancia.es/oia/esp/documentos ficha.aspx?id=3940

[Consultado: 25 de marzo de 2021].

Van Dijk, Teum

1991 Racism and the Press. Londres, Routledge.

Verón, Eliseo

2004 "A publicidade ou os mistérios da recepção", en Eliseo Verón, Fragmentos de um tecido. São Leopoldo/RS, Editora UNISINOS: 215-238.

2015 "Teoría de la mediatización: una perspectiva semio-antropológica", Cuadernos de Información y Comunicación (Madrid), vol. 20: 173-182. 